\title{
Developing a Conference Presentation: A Primer for New Library Professionals
}

\author{
Tanya Lisa Rogoschewsky \\ Branch Head \\ Connaught Library \\ Regina Public Library \\ trogoschewsky@reginalibrary.ca
}

\section{Abstract}

A step-by-step guide that leads new professionals through the process of creating a conference proposal and developing a successful presentation.

\section{Keywords}

public speaking; conferences; professional development

As librarians, we are committed to life-long learning; library conferences give us the opportunity to continue our learning by providing both educational programming and essential networking opportunities. The strength of any conference is in having a wide range of topics from professionals with diverse library experiences. We, as professionals, must actively contribute to the growing body of knowledge and experience. For new professionals, creating and presenting a conference session can be very daunting, especially if one is not actively involved in a research project or pilot program. However, the benefits of presenting at a conference are numerous: you are able to increase your profile within the library community, share your knowledge or research findings with a wider audience, make new contacts, expand your résumé and gain valuable public speaking skills. Conference presenters also often enjoy discounts on registration or room rates, making professional development opportunities more affordable.

This primer will walk you through the steps you need to consider in order to create an attractive conference proposal and successfully present your session. Remember that before you begin the process, you should speak with your supervisor about your intentions and any other considerations, such as travel time and budget.

\section{Step 1: Choose Your Conference}

There is a wide variety of national and international library conferences with either a specific geographical focus or specialized subject area. When identifying conferences of interest to you as a presenter, take into consideration both the purpose of the organization putting on the conference and the specific theme of the conference. 
Although conferences often have specific subject focuses, be careful not to limit yourself. WILU (Workshop for Instruction in Library Use) is often considered to be an academic conference, but librarians working in public or special libraries may be equally involved in information literacy instruction outside the traditional classroom setting.

You will also need to consider conference proposal submission deadlines. The call for session proposals is generally sent out between eight to ten months before the conference date. Proposal information may be sent out over various listservs, but, unless you plan to subscribe to most of them, checking conference or association websites is often easiest. A conference generally occurs annually at the same time of the year, so, once you have targeted a specific conference, you will have a sense of your timeline for preparing the proposal and developing the presentation.

\section{Step 2: Choose your Subject}

When deciding on a conference topic, you need to be familiar with current hot topics in librarianship. Spend some time reviewing professional literature and past conference topics. Conference committees are looking for sessions which contribute reliable or new knowledge in a particular area of librarianship and that deliver concrete benefits to participants. Be prepared to clearly outline how attendees will benefit from your session.

Common wisdom states that you should present on a subject that you are expertly familiar with, but consider reaching beyond your areas of direct expertise to broader topics of interest. As a new professional there might be few topics that you currently feel you have mastered but many subjects that you would like to learn more about. The study required to create a conference presentation on such a topic will considerably increase your knowledge, and your work will be of value to session attendees. In 2011, the author presented a conference session at the CLA (Canadian Library Association) conference entitled, "Who's In Charge Here? Tips \& Tricks for New Managers \& Supervisors." This topic was not chosen because the author was an expert in the field of management but because she was a new branch head for Regina Public Library and wanted to learn more strategies and tools for effective leadership. A conference presentation can be an excellent motivator for you to do the research and education you want, but which get over-shadowed by day-to-day responsibilities.

\section{Step 3: Choose your Format}

Once you have chosen your topic, you will need to decide which type of presentation you would like to make. There are four basic types of conference presentation:

- Standard Presentation: Generally a conference presentation is approximately one hour and involves a lecture supported by visual images (PowerPoint, graphs, photographs, etc.) with some time at the end for questions. 
- Workshop Presentation: Similar to a standard presentation, but with the expectation that the delegates will spend at least half the presentation actively participating in exercises, hands-on activities or practicing a new skill.

- Panel Presentation: A panel presentation involves three to five presenters each given 10 to 15 minutes to discuss a topic as it relates to their institution or region. If you are nervous about presenting individually, a panel presentation can be less demanding since the presentation time is divided among several people. Ideally, the members of a panel will offer differing perspectives on the same topic, so be thoughtful when choosing who to invite to submit a presentation with you. A panel presentation can be a wonderful way to network with other librarians, but working with a larger number of people will also mean more effort developing and organizing a seamless presentation.

- Poster Presentation: A poster presentation is a visual presentation of ideas using charts, graphs, photographs or diagrams interspersed with text.

Posters are generally displayed for the entire conference with a specific time set aside for delegates to meet and question the poster creator. This can be a wonderful way to ease into presenting at conferences or an option for those whose skill set does not include public speaking.

\section{Step 4: Prepare Your Proposal}

Once you have chosen your topic and your format, you will need to develop your conference proposal. Review the call for proposals very carefully since every conference will have different requirements for what must be included in the proposal and how that information is to be organized. The conference committee may also list the criteria used to evaluate proposals. It is also advantageous to review the conference website and the sponsoring organization's website or journal. The organization's philosophy or mission statement may help you determine the focus of the conference. If the conference has a particular theme, you should clearly show how your presentation fits into that theme.

Ensure your proposal follows all the guidelines. As with all written communication, clarity matters. Use concrete and specific language; be concise, and decisively state your topic and the benefits to delegates. A committee may review hundreds of conference proposals; you want your proposal to be both memorable and professional.

Many calls for proposals will also ask you to submit a conference "blurb". This is the description of your session that will be printed verbatim in the conference program. Think of your blurb as an advertising tool. The goal of the blurb is to convince delegates to choose your conference session over the many other sessions being offered. The blurb should be exciting and engaging while communicating the theme of the session and identifying the goals and the expected outcomes for participants. 


\section{Step 5: Prepare your Conference Presentation}

Once you have been selected to present, it is time to develop your presentation. Start by identifying the three to five main points that you want the audience to remember from your session. Next, you want to develop an outline for your presentation which will help you organize your information into a smooth progression of ideas.

For example, a session that details a pilot project should include:

- An account of library status-quo prior to the project (the rationale behind the project)

- A description of the pilot program including the proposed objectives, the timelines, the outcomes and evaluation criteria

- Results of the pilot program - both the successes and the failures

- Information on how the pilot program led to improved services, collections, customer satisfaction, etc.

- Information on how the pilot project can be adapted for other libraries

A lesson planning approach is to use BOPPPS, which stands for bridge, objective, pretest, participatory learning, post-test, summary. ${ }^{1}$ BOPPPS is a popular model for educational presentations or workshops because it provides a strong skeleton structure which includes the basic elements of successful instruction.

The bridge is your opening activity or statement. It can be humorous, shocking or thought-provoking as long as it generates interest in your topic and motivates the participants to pay attention. Once you have your audience's attention, you can give them your presentation's objective. The objective should succinctly state what the audience will learn from your presentation. Clearly communicating what attendees can expect to learn helps to focus participants' attention and also gives them a basis for evaluating the presentation's success. An example is: "At the end of this session, participants will have learned how to handle four of the most common problems library managers face."

The pre-test is generally a series of questions that you will pose to the audience allowing you to gauge participants' familiarity with the topic. It allows you to measure learning throughout the session and gives you the opportunity to adjust the depth and pace of your presentation to fit a particular group of learners. Participatory learning is where you will spend the majority of your time during the presentation. It is called participatory because, although you will be providing the information, the presentation should include strategies that encourage participants to actively consider and process the new information rather than passively receive it. This can consist of time for critical discussion, evaluation of case studies, role playing or small group activities.

\footnotetext{
${ }^{1}$ UBC Health Library Wiki [wiki on Internet]. BOPPPS model [wiki article] [accessed 15 Oct 2011]. Available from: http://hlwiki.slais.ubc.ca/index.php/BOPPPS_Model
} 
The post-test is an assessment tool which allows you to check whether your presentation has fulfilled its objectives. Assessment strategies can include short multiple-choice or true/false questions, checklists, attitude scales or learner demonstrations. In an average one-hour conference presentation you may not always have time to conduct a full post-test, but including some basic questions that can be answered with a show of hands can give you informal information on whether your presentation was successful. The summary is a quick content review that provides a sense of closure and completion for the participants while giving you one final opportunity to ensure your message has been received.

Remember, organizations are investing a substantial amount of time and money in order to send delegates to a conference, and they will care about results. Your session should deliver education that leads to improved performance, improved services and improved results.

Take advantage of the wealth of information available on how to create powerful PowerPoint slides that enhance rather than detract from your presentation. New presenters tend to put all of the relevant information on their slides and then simply narrate them, but the PowerPoint is not the presentation.

Also consider developing a handout as opposed to simply giving participants a copy of your PowerPoint slides. Effective slides have minimal text and more eye-catching graphic imagery such as photographs and charts. In contrast, a handout should give attendees the vital information from your session in greater detail so that they can review your presentation points in the future and take your message back to their home institutions.

When preparing your presentation, make sure that you have received the following information from the conference organizing committee:

- What audio-visual and sound equipment is provided by the conference and what will you need to provide yourself?

- Will the room have internet access?

- Will the conference provide handouts for the session? If yes, when will they need the master copy and in what format?

- Will you be given advance information on the number of delegates registered for your session?

- How is the room set up?

- Is it possible to get access to the room in advance or is your session immediately following another presentation?

\section{Step 6: Delivering your Presentation}

A presentation is a performance, and posture, eye-contact, confidence, speaking style, as well as the energy and enthusiasm of the speaker, are all important in engaging the attention of the audience. In fact, your speaking style and energy will be as important to the audience as your information. A monotonous presentation may be full of useful 
information, but if your audience has mentally "left the building" none of that information is being successful conveyed.

Rather than having a one-way flow of information, consider your session as a conversation with many people instead of just one. Include provocative questions that encourage your audience to think about the topic in a new way. Illustrate your points with examples: abstract concepts and ideas are more easily absorbed when there are stories that demonstrate them in real-world situations.

You have limited time in a conference session, so choose your material appropriately and be wary of trying to cram in too much. You need to ensure that you have allotted adequate time for introductions, warm-up activities and questions. It is more effective to make fewer points, but make them clearly by using examples, metaphors or analogies. It is very frustrating to participants to have a talk that goes over the time limit or to attend a session in which a presenter is forced to abandon or skim over slides in order to stay within the time constraints.

Practice giving your complete presentation several times. Not only will this allow you to judge whether you have timed your presentation correctly, but it will build your speaking confidence so that at the conference you can deliver it smoothly, without reading it or rushing through it. Ideally your speaking notes should serve as a guide rather than a detailed map of every word you are going to say. A speaker who is directly reading from her presentation notes cannot truly engage the audience. Finally, assume that you will be asked questions following your presentation. If you can prepare answers for possible questions in advance, you are less likely to be flustered by an unexpected query. If you do not know the answer to a question, don't try to bluff. Answer honestly that you do not know or do not have experience with that type of scenario, but offer to take the participant's name and email address and follow-up on the inquiry.

\section{Step 7: Following-Up your Conference Presentation}

After the conference presentation has been successfully completed, take a few minutes to write down what questions were asked. Not only will this help you prepare if you decide to present this session at another event, but the questions may also give you ideas for future sessions. Stay in the room for some time after the presentation; many of the best networking opportunities will happen directly after your session with participants who enjoyed your presentation. Have plenty of business cards available, and if attendees ask you to follow up with additional information or the answer to a complex question, get their contact information and make a note of what they were looking for. It can be difficult to remember individual requests, but following up on them allows you to continue conversations and creates wonderful networking opportunities.

\section{Conclusion}

The process of successfully developing a conference proposal is more manageable when considered as a series of concrete steps. You will need to choose a specific 
conference and research that conference's area of focus and past presentation topics. When choosing your presentation topic, review current professional literature, and remember that a presentation can also serve as the catalyst for you to expand your knowledge on a particular topic. There are several common formats for conference presentations, and you should choose the format that allows you to present your information in the most comprehensible way.

When developing the proposal, review the selection criteria carefully, and be sure to include all relevant information, such as how your session would benefit conference attendees. When preparing the presentation, have clear learning objectives, and tailor your information appropriately to the time constraints. Your presentation should encourage participatory learning and include strategies such as real-life scenarios that make your information relevant to participants. While the majority of your work will involve preparing the actual presentation and handout, remember to take time after your presentation to record questions and to network with attendees.

Presenting at a conference is one of the most beneficial career moves you can make. Not only are you able to share information on a subject you are passionate about or a project you are proud of, but you will get the opportunity to meet others who are enthusiastic about and interested in your work. Conference presentations allow you to contribute to critical discussions in librarianship and share your research or innovative programming with the broader library community. Presenting at different national or international conferences will also expose you to a wider range of ideas and topics and expand your networking opportunities. Your discussions could lead you to discover a new colleague to collaborate with or a potential job opportunity. With the range of potential benefits, developing a conference proposal and presentation is well worth the investment of time and energy.

\section{Further Reading on Developing Successful Presentations:}

Belben, Cathy. "Making a gift of yourself: preparing for successful conference presentations." Teacher Librarian 31.1 (2003): 12+. Expanded Academic ASAP. Web. 19 Oct. 2011.

DeFoe, Tory. "The Truth Is, You Gave a Lousy Talk." The Chronicle of Higher Education 54.17 (2007). Expanded Academic ASAP. Web. 10 Sept. 2011.

DePasquale, Paula, Carolyn Dickson, and Doug Malouf. "The seven deadly sins of speakers." Training \& Development (1995): 13+. Expanded Academic ASAP. Web. 06 Sept. 2011.

Dzurinko, Mary K. "Giving presentations with pizazz." Information Outlook Apr. 1999: 34+. Expanded Academic ASAP. Web. 15 Oct. 2011.

Harris, Richard M. "Practically perfect presentations." Training \& Development July 1994: 55+. Expanded Academic ASAP. Web. 15 Oct. 2011. 
Linney, Barbara J. "Presentations that hold you spellbound. (Career Management)." Physician Executive Sept.-Oct. 2000: 72+. Expanded Academic ASAP. Web. 06 Sept. 2011

Spaeth, Marie. "On Presentations." Risk Management Apr. 2001: 9. Expanded Academic ASAP. Web. 15 Oct. 2011

Zigelstein, Trevor. "Developing Effective Presentation Skills." CMA Magazine 76.2 (2002): 8-. CBCA Business. Web. 24 Oct. 2011.

\section{Further Reading on Using PowerPoint Effectively:}

Clark, Jennifer. "Powerpoint and pedagogy: maintaining student interest in university lectures." College Teaching Winter 2008: 39+. Expanded Academic ASAP. Web. 15 Oct. 2011.

Cooper, Adam. Powerpoint Presentations That Sell: Simple Techniques To Plan, Design And Deliver Sales Presentations That Get Results. Toronto: McGraw-Hill Companies, 2009

Griggs, K. "Creating dynamic multimedia presentations: Using Microsoft PowerPoint." Business Communication Quarterly 65.2: 118-21. ProQuest. Web. 11 Sept. 2011.

Perry, A. E. "PowerPoint presentations: A creative addition to the research process." English Journal (2003) 92.6: 64. Expanded Academic ASAP. Web. 15 Oct. 2011.

Tufte, E. PowerPoint Is Evil: Power Corrupts. PowerPoint Corrupts Absolutely. Wired Magazine. 2003, September http://www.wired.com/wired/archive/11.09/ppt2.html (accessed 29 April 2004) 